\title{
OPERATIONAL MODELING: OCEAN MODELING AT THE FLEET NUMERICAL OCEANOGRAPHY CENTER
}

\author{
By R. Michael Clancy
}

$\mathrm{R}$

EFLECTING the organization's growing responsibilities and capabilities in oceanography, ocean modeling, and coupled air-sea modeling, Fleet Numerical Weather Central, Monterey, was redesignated as the Fleet Numerical Oceanography Center (FNOC) in 1979. In addition to being a world-class global weather prediction center, FNOC is now widely regarded as the leading source of operational oceanographic information in the world. Indeed, it is this emphasis on oceanography that distinguishes FNOC from all other operational weather prediction centers. No other center has FNOC's responsibility for predicting the global environment from the top of the stratosphere to the bottom of the ocean, and no other center has as complete an air-sea data base.

FNOC operates around the clock, 365 days a year, providing services to United States and allied naval forces, other components of the Department of Defense, and a broad spectrum of civilian interests. The center operates a sophisticated suite of numerical oceanographic and atmospheric models and satellite processing software in a multimainframe supercomputer environment. Products are distributed to users around the world, both ashore and afloat, through a variety of communications networks.

In general, accurate representation of oceanic physics, data assimilation, and coupling with atmospheric models via air-sea heat and momentum fluxes are major issues associated with the ocean models in use at FNOC. Research and development $(R \& D)$ support for these models is coordinated through the Navy Ocean Modeling and Prediction (NOMP) program. The supporting R\&D is performed mainly by the Oceans and Atmosphere Directorate of the Naval Research Laboratory (NRL). A formal and highly structured process exists for making the transition of models from R\&D at NRL into operations at FNOC.

R. M. Clancy, Ocean Models Division, Fleet Numerical Oceanography Center, Monterey, CA 93943, USA.
FNOC's emphasis on treating the global atmosphere and ocean as a coupled system makes its operational models and data bases important national resources for monitoring and studying climate and global change. Largely because of this, the National Oceanic and Atmospheric Administration (NOAA) established the Center for Ocean Analysis and Prediction (COAP) in collocation with FNOC in 1988. COAP facilitates civilian access to FNOC air-sea products and fosters their use in a wide range of research applications.

\section{Operational Use of Ocean Models}

More than a dozen ocean model systems run operationally at FNOC (Clancy, 1987; Clancy and Sadler, 1992). Some run on global grids with relatively coarse spatial resolution, and others function on limited-area grids with fine-scale spatial resolution applied in geographical areas of particular Navy interest. All of the ocean models are fully automated and operated on a fixed schedule, with most run once per day. The hardware, software, data base, communications, and manpower infrastructure necessary to support operation of these models overlaps substantially and naturally with that required to support the weather prediction models in use at the center.

The FNOC ocean models fall into three general categories: thermal structure and circulation, sea ice, and sea state. The thermal-structure and circulation models depict ocean fronts and eddies and provide input to acoustic models, which predict the performance of the Navy's acoustic sensors. In addition, they provide the sea-surface temperature (SST) boundary condition for atmospheric models, and predict surface currents in support of ocean search and rescue and optimum-track ship routing. The sea-ice models predict ice thickness, concentration, and drift in support of the Navy's arctic operations. Finally, the sea-state models predict directional wave-energy spectra, from which wave height, period and direction fields are derived in support of ship routing and a variety of other activities.
More than a dozen
ocean model systems
run operationally at
FNOC [Fleet Numerical
Oceanography Center] 
Emphasis is placed on using the ocean models to convert well-observed surface oceanographic or atmospheric information into an accurate representation of oceanographic fields for which observations are sparse or nonexistent. For example, the surface positions of fronts and eddies observed by satellites are used to map subsurface salinity and thermal structure via synthetic data and ocean-feature models in the Optimum Thermal Interpolation System Version 3.0 (OTIS 3.0) analysis (Cummings and Ignaszewski, 1991). Surface wind stresses and heat fluxes provided by FNOC atmospheric models are used to predict mixed-layer depth and surface currents via the vertical mixing parameterizations in the Thermodynamic Ocean Prediction System (TOPS) model (Clancy and Pollak, 1983). This atmospheric forcing is also used to predict ice thickness and drift via the dynamics and thermodynamics in the Polar Ice Prediction System (PIPS) model (Preller and Posey, 1989). Finally, surface winds
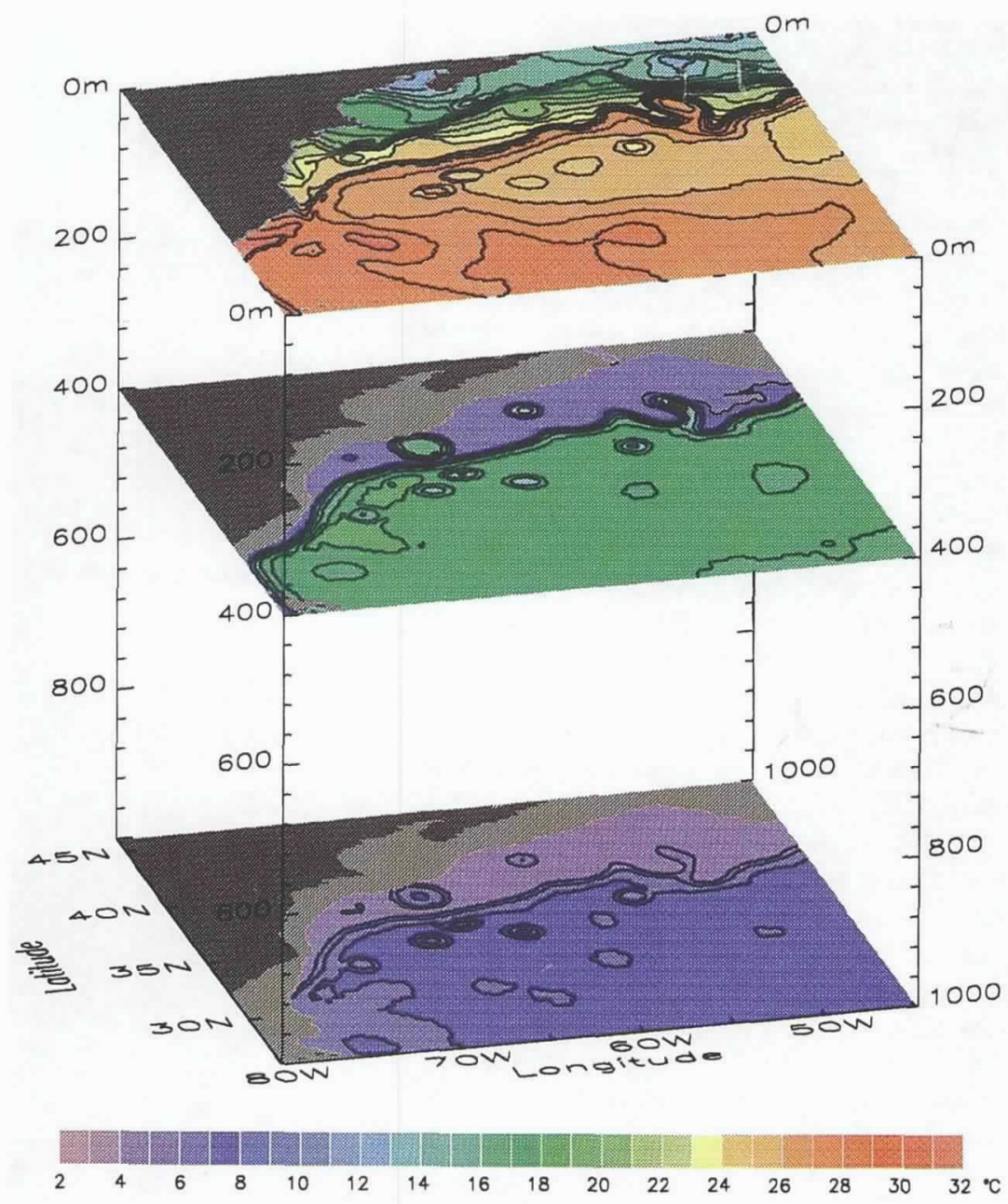

Fig. 1: Temperature at 0, 400, and 1,000 $\mathrm{m}$ depth in the Gulf Stream region from Version 3.0 of the Optimum Thermal Interpolation System (OTIS) model on 26 July 1991. The contour interval is $1^{\circ} \mathrm{C}$, and the color bar indicates temperature ranges in ${ }^{\circ} \mathrm{C}$. and wind stresses from the atmospheric models are used to predict directional wave-energy spectra via the wave physics in the Global Spectral Ocean Wave Model (GSOWM) (Clancy et al., 1986) and the third-generation wave model (WAM) (WAMDI Group, 1988). Thus, the models augment the extremely sparse in situ oceanographic data in a substantial way by inferring oceanographic information from other sources. Through these sophisticated processes, the models are able to provide a much more accurate and complete representation of the ocean than could be obtained from either oceanographic climatology alone, realtime oceanographic data alone, or a simple combination of the two.

\section{Example Output}

The OTIS 3.0 ocean thermal model (Cummings and Ignaszewski, 1991; Clancy et al., 1991) generates synthetic subsurface data from the surface positions of fronts and eddies observed in satellite imagery and a water-mass-based representation of historical bathythermograph data. Used in conjunction with "ocean-feature models," which describe the transition between water masses across frontal boundaries, and the optimum-interpolation data-assimilation technique, these synthetic data allow OTIS 3.0 to produce a rather accurate three-dimensional analysis of the ocean mesoscale. An example is presented in Figure 1 , which shows the temperature at 0,400 , and $1,000 \mathrm{~m}$ produced by OTIS 3.0 in the Gulf Stream region on 26 July 1991. The subsurface representation of the Gulf Stream front and associated eddies evident in the figure could not be derived from available in situ data. It is a direct result of the model's translation of surface information (satellite-observed surface positions of features) into subsurface information (synthetic subsurface data). Note that several of the features in Figure 1 exhibit stronger horizontal temperature gradients at depth than at the surface, which is characteristic of summertime conditions in this region.

The PIPS sea-ice model (Preller and Posey, 1989; Preller, 1992, this issue) is based on the formulation of Hibler (1979) and contains a sophisticated treatment of ice dynamics and thermodynamics. Ice thickness and drift from the basinscale PIPS model for 1 March 1990 are shown in Figure 2. Vigorous cyclonic ice drift, driven by a strong atmospheric low-pressure system, is present in the eastern arctic, while the central and western arctic are relatively quiescent. The model predicts the thickest ice along the Canadian Archipelago, with relatively thin ice along the ice edge and in the Kara and Barents Seas. The detached circular region of thin ice off the northeast coast of Greenland is the seasonally recurring "Odden" feature (Vinje, 1983), which reflects the circulation in the Greenland Sea Gyre. 
The GSOWM sea-state model (Clancy et al., $1986)$ is based on the linear "first-generation" wave physics of Pierson (1982). An example of GSOWM output is shown in Figure 3, which depicts a directional wave-energy spectrum predicted by the model at a point in the northwest Atlantic during the Labrador Extreme Waves Experiment (LEWEX). This bimodal spectrum reflects propagation of swell from the northwest and windsea from the east. The swell energy is dying while the sea energy is growing in response to a $17 \mathrm{~m} \mathrm{~s}^{-1}$ easterly wind. The height, period, and direction derived from the model spectrum are $4.4 \mathrm{~m}, 10$ $\mathrm{s}$, and $86^{\circ}$ for the sea and $2.5 \mathrm{~m}, 11 \mathrm{~s}$, and $334^{\circ}$ for the swell. The significant wave height derived from the model spectrum is $5.0 \mathrm{~m}$.

\section{Model Validation}

A model undergoes a formal and sometimes lengthy Operational Test (OPTEST) before it is accepted for operational use. The primary purpose of the test is to demonstrate that the model runs reliably in the operational jobstream and produces a useful product from operationally available data inputs. Generally a model under OPTEST is intended to replace an existing operational model, and in these cases it also must be demonstrated that products from the new model are an improvement over those provided by the old model.

A wide variety of data are used for validation. For example, the ocean thermal and circulation models are validated with bathythermograph, satellite Multi-Channel Sea Surface Temperature (MCSST) and ship data (Clancy et al., 1990, 1992), and drifting buoy data (deWitt et al., 1989). The sea-ice models are validated with drifting buoy data, submarine ice-thickness data, and analyses of ice concentration and drift derived from satellite data (Preller and Posey, 1989; Fett, 1990; Emery et al., 1991). The sea-state models are validated with buoy, ship, and satellite altimetry data (Clancy et al., 1986; Pickett et al., 1986; Rao, 1989; Wittmann and Clancy, 1991a,b).

An example of ocean-thermal-model validation is shown in Figure 4. This figure shows a 2-month time series of root-mean-square (rms) errors for the FNOC regional SST field in the western North Atlantic. It is based on comparison of approximately four to six bathythermograph observations made in the region each day with the previous day's analyzed SST field (thus, the SST validated on each day is independent of the validation data). During the first 29 days of the period (red curve), the SST field was produced by the OTIS 2.0 model, and the rms error averaged about $2.2^{\circ} \mathrm{C}$. The more advanced OTIS 3.0 model (Cummings and Ignaszewski, 1991) was implemented on 30 August 1990, and the resulting rms errors (blue curve) reflect this improvement, averaging only about $1{ }^{\circ} \mathrm{C}$ during the last 30 days of the record.

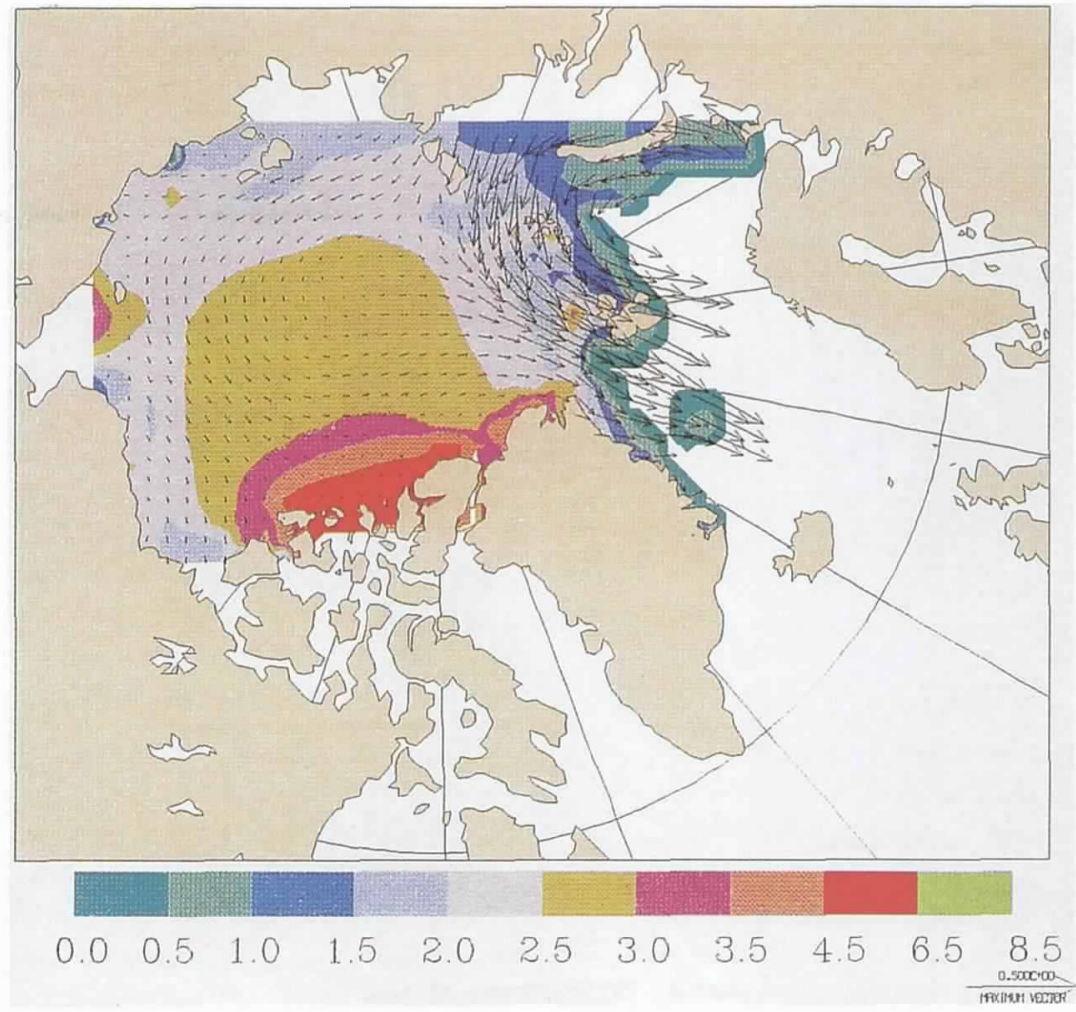

Fig. 2: Ice thickness (color) and ice drift (vectors) from the Polar Ice Prediction System (PIPS) model on 1 March 1990. The color bar indicates ice thickness ranges in meters, and the reference vector at the lower right corner defines ice drift of $0.5 \mathrm{~m} \mathrm{~s}^{-1}$.

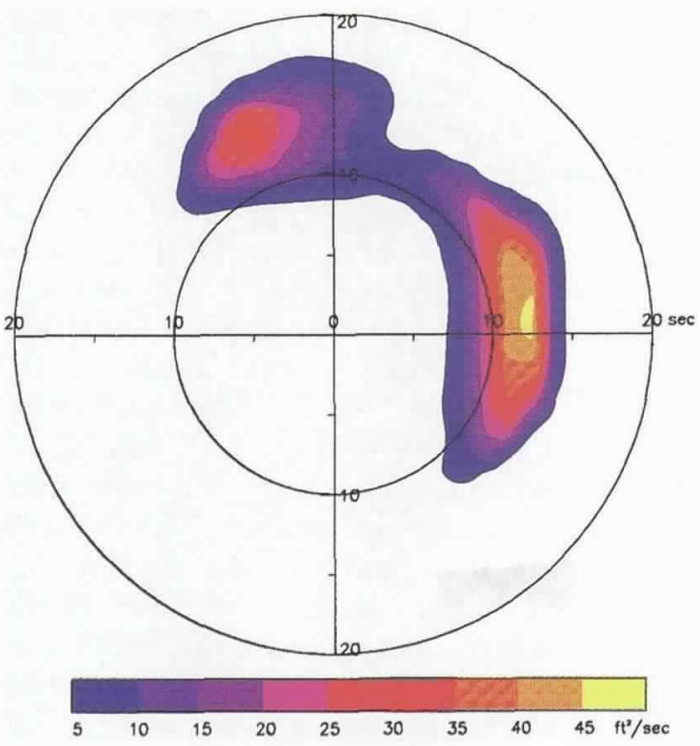

Fig. 3: Directional wave energy spectrum from the Global Spectral Ocean Wave Model (GSOWM) for $50.0^{\circ} \mathrm{N}, 47.5^{\circ} \mathrm{W}$ at $1200 \mathrm{GMT}, 13$ March 1987. Azimuth indicates the direction from which wave energy is coming and radius gives the wave period in seconds. The color bar indicates wave energy ranges in $\mathrm{ft}^{2} \mathrm{~s}^{-1}$. 
RMS Error (Deg C)

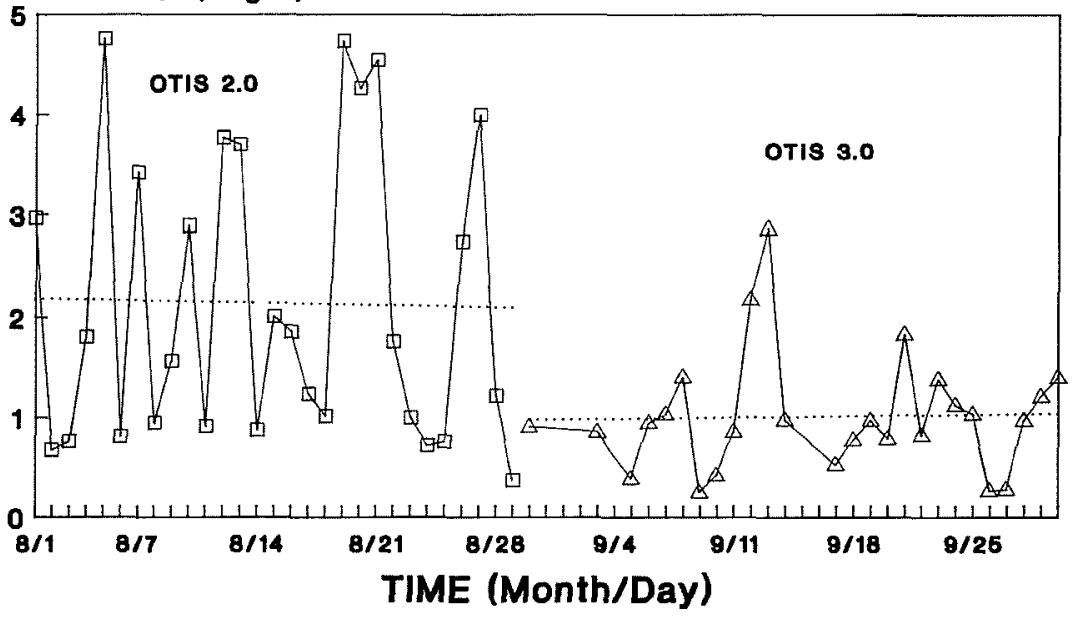

$\square$ OTIS 2.0 SST Error $\triangle$ OTIS 3.0 SST Error … Linear Regreasion

Fig. 4: Time series of root-mean-square errors for the Fleet Numerical Oceanography Center (FNOC) regional sea-surface temperature field in the western North Atlantic $\left(26-46^{\circ} \mathrm{N}, 50-80^{\circ} \mathrm{W}\right)$ from 1 August through $30 \mathrm{Sep}$ tember 1990 based on comparison of daily model-analyzed fields with unassimilated bathythermograph data. Errors for Versions 2.0 and 3.0 of the OTIS model are shown in red and blue, respectively. The least-squares regression lines through the two error curves are shown as dotted black lines.

Parallel runs of OTIS 2.0 and 3.0 using exactly the same data inputs for an earlier time period also confirm the improvement provided by the new model (Clancy et al., 1991).

\section{Summary and Outlook}

FNOC has provided real-time oceanographic products to the US Navy for over 25 years and currently operates many numerical ocean models. These models are fully automated, operated on a fixed schedule, and characterized by close, and in some cases weakly two-way interactive, coupling with atmospheric models.

Most of the ocean models at FNOC run on a Cyber 205 computer, which is currently at full saturation and beyond the end of its planned life cycle. A Cray Y-MP C90 supercomputer will be installed at FNOC in 1992 to replace the Cyber 205 . The speed and memory afforded by this new machine will allow major advances in the center's ocean prediction capabilities. Specifically, the OTIS thermal-analysis model, the TOPS mixedlayer model, and ocean-circulation models under development through the NOMP Program will be fully coupled with one another and run on eddy-resolving grids with basin-scale and, eventually, global-scale coverage. Assimilation of seasurface-height data from satellite altimeters will then become a key issue in the resulting global eddy-resolving ocean-prediction system (Hurlburt, 1984). The spatial resolution of the basinscale PIPS ice model will be increased to allow accommodation of mesoscale wind patterns, and it will be coupled with an underlying ocean-circulation model to achieve a better representation of ocean currents and ice-ocean heat fluxes in the arctic. The WAM wave model will be implemented to achieve global application of its advanced third-generation physics at a spatial resolution of $1^{\circ}$ latitude by $1^{\circ}$ longitude or finer. Higher-resolution regional versions of WAM will be coupled with surface currents provided by the ocean thermal-structure and circulation models to account for wave-current interactions, often important in damaging wave events. In addition, techniques will be implemented to assimilate synoptic wave data from a variety of sources directly into WAM.

By the late 1990s, the ocean thermal, sea-ice, and wave models will be merged into the global atmospheric model at FNOC to produce a software-integrated, fully coupled, and two-way interactive air-sea model. By coupling the ocean and atmospheric models in this manner, exchange of boundary-condition information between the models at every time step and joint air-sea data assimilation will be possible, leading to a more accurate representation of air-sea heat and momentum fluxes. This will improve modeling of conditions near and on either side of the air-sea interface (where the majority of critical Naval operations occur) and contribute to the extension of numerical atmospheric and oceanographic forecast skill.

The resulting real-time air-sea products from FNOC will provide both direct and indirect support of the third-generation Tactical Environmental Support System [TESS (3)], which will be deployed on the Navy's major combatants and at selected shore sites in the early 1990s. These products, highly compacted for efficient communication (Garthner et al., 1991), will supply first-guess fields, initial conditions, boundary conditions, and synthetic data for local-scale models run on TESS (3). By complementing its global-scale and regional-scale mainframe-class models at FNOC with local-scale workstationclass models on TESS, the Navy will achieve an accurate, responsive, and survivable configuration for its overall environmental prediction support system.

Although FNOC's primary responsibility is to support Naval operations, its oceanographic products can contribute to the fulfillment of broader national requirements (National Research Council, 1989). For example, as a global operational air-sea prediction center, FNOC carries out global environmental monitoring on a routine daily basis. The advances in ocean modeling discussed above will enhance further this global monitoring capability by providing an improved framework for assimilating and interpreting global oceanographic data. In particular, the ocean 
models expected to be operational at FNOC in the mid- to late 1990 s will provide the means to assimilate satellite altimetry data into a complete depiction of the ocean mesoscale, which may be an important contributor to the global heat balance.

\section{Acknowledgements}

The contributions of the following personnel to the Oceanography Program at FNOC are gratefully acknowledged: Jim Cummings, Webb deWitt, Andy Hergert, Mark Ignaszewski, Paul May, Bruce Mendenhall. Tom Pham, Ken Pollak, Pete Tunnicliffe, and Paul Wittmann. Special thanks to Ruth Preller, Paul May, and Paul Wittmann for providing Figures 1-3.

\section{References}

Clancy, R.M. and K.D. Pollak, 1983: A real-time synoptic ocean thermal analysis/forecast system. Progr. Oceanogr.. 12, 383-424.

, J.E. Kaitala and L.F. Zambresky, 1986: The Fleet Numerical Oceanography Center Global Spectral Ocean Wave Model. Bull. Am. Meteorol. Soc., 67, 498-512.

1987: Real-time applied oceanography at the Navy's global center. Mar. Technol. Soc. J., 2I, 33-46.

P.A. Phoebus and K.D. Pollak, 1990: An operational global-scale ocean thermal analysis system. J. Atmos. Ocean. Tech. 7, 233-254.

J.A. Cummings and M.J. Ignaszewski, 1991: New ocean thermal structure model operational at FNOC. Naval Oceanography Command News, vol. 11(5), 1-5.

J.M. Harding, K.D. Pollak and P. May, 1992: Quantification of improvements in an operational global-scale ocean thermal analysis system. J. Atmos. Ocean. Tech. 9. 55-66.

, and W.D. Sadler, 1992: The Fleet Numerical Oceanography Center suite of oceanographic models and products. Weather and Forecasting. 7(2).

Cummings. J.A. and M. Ignaszewski, 1991: The Fleet Numerical Oceanography Center regional ocean analysis system. In: Proceedings of the MTS 91 Conference, New Orleans, 1991, Marine Technology Society, 1828 L Street NW, Suite 906, Washington. DC 20036, $1123-$ 1129.

deWitt, P.W., R.M. Clancy and J.M. Harding, 1989: Surface current model validation using drifting buoys. In: Proceedings of the Marine Data Systems International Symposium. New Orleans, 1989, Marine Technology Society, 1828 L Street NW, Suite 906, Washington, DC 20036. 243-248.

Emery, W.J., C.W. Fowler, J.D. Hawkins and R.H. Preller, 1991: Fram Strait satellite image-derived ice motions. J. Geophys. Res., 96, 4751-4768.
Fett, R.W., 1990: Satellite applications in the arctic. In: Preprint Volume of the Fifth Conference on Satellite Meteorology and Oceanography, 1990, American Meteorological Society, Boston, 421-425.

Garthner, J.P., B.R. Mendenhall and R.M. Clancy, 1991: Navy Oceanographic Data Distribution System (NODDS) access and display of three-dimensional oceanographic fields. In: Proceedings of the MTS'91 Conference, New Orleans, 1991, Marine Technology Society, 1828 L Street NW, Suite 906, Washington, DC 20036, 128 133.

Hibler, W.D., 1979: A dynamic thermodynamic sea ice model. J. Phys. Oceanogr., 9, 815-846.

Hurlburt, H.E., 1984: The potential for ocean prediction and the role of altimeter data. Mar. Geod., 8, 17-66.

National Research Council, 1989: Opportunities to Improve Marine Forecasting. National Academy Press, 2101 Constitution Ave. NW, Washington, DC 20418, 125 pp.

Pickett, R.L., D.L. Burns and R.D. Broome, 1986: Comparisons of wind and wave models with GEOSAT: Final report. Technical Report 201, Naval Oceanographic and Atmospheric Research Laboratory, Stennis Space Center, MS 39529, 12 pp.

Pierson, W., 1982: The Spectral Ocean Wave Model (SOWM), a northern hemisphere computer model for specifying and forecasting ocean wave spectra. Technical Report DTNSRDC-82/011, David W. Taylor Naval Ship Research and Development Center, Bethesda, MD 20084, $186 \mathrm{pp}$.

Preller, R.H., 1992: Sea ice prediction-The development of a suite of sea ice forecasting systems for the northern hemisphere. Oceanography, 5, 64-68.

Preller, R.H. and P.G. Posey, 1989: The Polar Ice Prediction System-A sea ice forecasting system. NORDA Report 212, Naval Oceanographic and Atmospheric Research Laboratory, John C. Stennis Space Center, MS 39529, $42 \mathrm{pp}$.

Rao, D.B., 1989: A review of the program of the Ocean Products Center. Weather and Forecasting, 4, 427-443.

Vinje. T.E., 1983: Sea ice conditions in 1982. Aarb. Nor. Polarinst., 5, 49-53.

WAMDI Group, 1988: The WAM model-A third generation ocean wave prediction model. J. Phys. Oceanogr., 18 $1775-1810$

Wittmann, P.A. and R.M. Clancy, 1991a: Implementation and validation of a third-generation wave model for the Mediterranean Sea. In: Proceedings of the MTS'9l Conference, New Orleans, 1991, Marine Technology Society, 1828 L Street NW, Suite 906, Washington, DC 20036, 154-158.

Wittmann, P.A. and R.M. Clancy, 1991b: Global Spectral Ocean Wave Model predictions during LEWEX. In: Directional Ocean Wave Spectra. R.C. Beal, ed., The Johns Hopkins University Press, Baltimore, MD 147 151. [
. . . models . . . will

provide the means to

assimilate satellite

altimetry data into a

complete depiction

of the ocean

mesoscale. 